\section{(2) OPEN ACCESS}

\title{
Chronic obstructive pulmonary disease and lung cancer incidence in never smokers: a cohort study
}

\author{
Hye Yun Park, ${ }^{1}$ Danbee Kang, ${ }^{2,3}$ Sun Hye Shin, ${ }^{1}$ Kwang-Ha Yoo, ${ }^{4}$ Chin Kook Rhee, ${ }^{5}$ \\ Gee Young Suh, ${ }^{1}$ Hojoong Kim, ${ }^{1}$ Young Mog Shim, ${ }^{6}$ Eliseo Guallar, ${ }^{7}$ Juhee Cho, $, 3,7$ \\ 0 Jung Kwon ${ }^{1}$
}

For numbered affiliations see end of article.

\section{Correspondence to}

Dr Juhee Cho, Center for Clinical Epidemiology, Samsung Medical Center, Seoul 06351, South Korea; jcho@skku.edu

HYP and DK contributed equally. $J C$ and OJK contributed equally.

Received 20 June 2019 Revised 25 November 2019 Accepted 31 December 2019 Published Online First 2 April 2020
Check for updates

(C) Author(s) (or their employer(s)) 2020. Re-use permitted under CC BY-NC. No commercial re-use. See rights and permissions. Published by BMJ.

To cite: Park HY, Kang D, Shin $\mathrm{SH}$, et al. Thorax 2020:75:506-509.

\section{ABSTRACT}

There has been limited evidence for the association between chronic obstructive pulmonary disease (COPD) and the incidence of lung cancer among never smokers We aimed to estimate the risk of lung cancer incidence in never smokers with COPD, and to compare it with the risk associated with smoking. This cohort study involved 338548 subjects, 40 to 84 years of age with no history of lung cancer at baseline, enrolled in the National Health Insurance Service National Sample Cohort. During 2355005 person-years of follow-up (median follow-up 7.0 years), 1834 participants developed lung cancer. Compared with never smokers without COPD, the fullyadjusted hazard ratios $(95 \% \mathrm{Cl})$ for lung cancer in never smokers with COPD, ever smokers without COPD, and ever smokers with COPD were 2.67 (2.09 to 3.40), 1.97 (1.75 to 2.21$)$, and 6.19 (5.04 to 7.61), respectively. In this large national cohort study, COPD was also a strong independent risk factor for lung cancer incidence in never smokers, implying that COPD patients are at high risk of lung cancer, irrespective of smoking status.

\section{INTRODUCTION}

Chronic obstructive pulmonary disease (COPD) is associated with increased lung cancer development, ${ }^{1}$ but this association remains unclear in never smokers. While up to $39 \%$ of COPD patients are never smokers, ${ }^{2}$ there is very limited evidence on the association between COPD and lung cancer incidence in this group, as most studies used crosssectional or case-control designs and included relatively few never smokers. ${ }^{13}$ In two cohorts, COPD was a significant predictor of incident lung cancer, but the number of incident cases of lung cancer in never smokers with COPD in each cohort was $<10$. ${ }^{45}$ We used data from a large nationally representative cohort to evaluate the risk of lung cancer incidence associated with COPD by smoking status. Our main objective was to estimate the risk of lung cancer incidence in never smokers with COPD, and to compare this risk to never smokers without COPD, ever smokers without COPD, and ever smokers with COPD.

\section{METHODS}

\section{Study population and design}

We used data from the National Health Insurance Service (NHIS) National Sample Cohort, a population-based retrospective cohort study based on a representative sample of Korean citizens between 1 January 2002 and 31 December $2013 .^{6}$
We included all men and women, 40 to 84 years of age, who underwent at least one health screening examination provided by the NHIS during the study period $(n=370$ 617). We excluded participants who had cancer $(n=8999)$ before the first screening exam (baseline), or who had missing values for body mass index or smoking status at the baseline exam $(n=23070)$. The final sample size was 338548 participants (146996 men and 191552 women). The Institutional Review Board of the Samsung Medical Centre approved this study and waived the requirement for informed consent as we used only de-identified data.

\section{Data sources}

NHIS claims for inpatient visits, outpatient visits, procedures and prescriptions were coded using the International Classification of Diseases, 10th Revision and the Korean Drug and Anatomical Therapeutic Chemical Codes. ${ }^{7}$ Lung cancer was defined as the presence of the same C33 or C34 code more than three times within a year or an inpatient hospitalisation with a C33 or C34 code. $^{8}$ COPD was defined as the presence of J43-J44 (except J43.0) codes and use of COPD medications at least twice within a year. ${ }^{9}$ Smoking habits were measured by self-administered questionnaires at the baseline screening examination and categorised as never or ever.

\section{Statistical analysis}

The study endpoint was lung cancer incidence. Participants were included at the baseline screening examination and followed-up until the development of cancer, death, or the end of the study period (31 December 2013). The study exposure was COPD, considered as a time-varying variable. To account for competing risks due to mortality, we fitted a proportional subdistribution hazards regression model for lung cancer incidence associated with COPD with death as a competing event and age as the time scale. Regression models were adjusted for sex, body mass index and Charlson comorbidity index. We considered a value of $\mathrm{p}<0.05$ as statistically significant. All analyses were performed using STATA version 14 (StataCorp LP, College Station, TX, USA).

\section{RESULTS}

Compared with participants without COPD, those who had COPD were older, more likely to be male, smokers, and to have a lower income and more comorbidities (table 1). During 2355005 
Table 1 Characteristics of study participants at the beginning of follow-up $(n=338548)$

\begin{tabular}{|c|c|c|c|c|}
\hline \multirow[b]{2}{*}{ Baseline characteristic } & \multirow[b]{2}{*}{ Overall $(n=338548)$} & \multicolumn{2}{|l|}{ COPD* } & \multirow[b]{2}{*}{$P$ value } \\
\hline & & No $(n=326169)$ & Yes $(n=12379)$ & \\
\hline Sex & & & & $<0.001$ \\
\hline Male & $146996(43.4)$ & $140581(43.1)$ & $6415(51.8)$ & \\
\hline Female & 191552 (56.6) & $184588(56.9)$ & $5964(48.2)$ & \\
\hline Age (years) & $52.9(10.5)$ & $52.5(10.3)$ & $62.0(9.6)$ & $<0.001$ \\
\hline$<60$ & 247301 (73.1) & $243538(74.7)$ & $3763(30.4)$ & \\
\hline $60-69$ & $60595(17.9)$ & $55954(17.2)$ & $4641(37.5)$ & \\
\hline$\geq 70$ & 30652 (9.1) & $26677(8.2)$ & 3975 (32.1) & \\
\hline Income percentile & & & & $<0.001$ \\
\hline$\leq 30$ th & $72260(21.3)$ & $68991(21.2)$ & 3269 (26.4) & \\
\hline$>30$ th $-\leq 70$ th & $123133(36.4)$ & $118860(36.4)$ & $4273(34.5)$ & \\
\hline$>70$ th & $143155(42.3)$ & $138318(42.4)$ & 4837 (39.1) & \\
\hline Residential area & & & & $<0.001$ \\
\hline Metropolitan & $218442(64.5)$ & $212255(65.1)$ & $6187(50.0)$ & \\
\hline Rural & $120106(35.5)$ & $113914(34.9)$ & $6192(50.0)$ & \\
\hline Body mass index $\left(\mathrm{kg} / \mathrm{m}^{2}\right)$ & $23.92(3.13)$ & $23.93(3.12)$ & $23.78(3.39)$ & $<0.001$ \\
\hline Underweight & $9286(2.7)$ & $8569(2.6)$ & $717(5.8)$ & \\
\hline Normal & $126645(37.4)$ & $122082(37.4)$ & $4563(36.9)$ & \\
\hline Overweight & $87561(25.9)$ & $84678(26.0)$ & $2883(23.3)$ & \\
\hline Obese & $115056(34.0)$ & $110840(34.0)$ & $4216(34.1)$ & \\
\hline Smoking status & & & & $<0.001$ \\
\hline Never & $241633(71.4)$ & $233266(71.5)$ & $8367(67.6)$ & \\
\hline Past & $21818(6.4)$ & $21016(6.4)$ & $802(6.5)$ & \\
\hline Current & $75097(22.2)$ & $71887(22.0)$ & $3210(25.9)$ & \\
\hline Charlson comorbidity index & $0(0-1)$ & $0(0-1)$ & $1(0-1)$ & $<0.001$ \\
\hline 0 & $231106(68.3)$ & $223581(68.5)$ & $7525(60.8)$ & \\
\hline 1 & $72788(21.5)$ & $69896(21.4)$ & $2892(23.4)$ & \\
\hline$\geq 2$ & $34654(10.2)$ & $32692(10.0)$ & $1962(15.9)$ & \\
\hline
\end{tabular}

Values in the table are mean (SD), median (IQR) or $\mathrm{n}(\%)$.

We used $\chi^{2}$ tests, t-tests, or rank-sum tests for comparing patients with and without COPD for categorical and continuous variables, as appropriate.

${ }^{*}$ COPD patients include those with COPD at baseline and those who developed COPD over follow-up.

COPD, chronic obstructive pulmonary disease.

person-years of follow-up (median follow-up 7.0 years), we observed 290 incident cases of lung cancer in participants with COPD (incidence rate 4.9 per 1000 person-years) and 1544 cases in participants without COPD or before the development of COPD (incidence rate 0.7 per 1000 person-years) (table 2)thus, a total of 1834 participants developed lung cancer.

The risk of disease in never smokers with COPD was higher than that in ever smokers without COPD (figure 1). Compared

Table 2 Hazard ratios (95\% confidence intervals) for incident lung cancer associated with COPD ( $\mathrm{n}=338548)$

\begin{tabular}{|c|c|c|c|c|}
\hline & Person-years & No. of cases & $\begin{array}{l}\text { Incidence rate } \\
\text { (per } 1000 \text { person-years) }\end{array}$ & Subdistribution HR $(95 \% \mathrm{Cl})$ \\
\hline \multicolumn{5}{|l|}{ COPD status } \\
\hline None & 2296032 & 1544 & 0.7 & Reference \\
\hline COPD & 58972 & 290 & 4.9 & 3.12 (2.66 to 3.65$)$ \\
\hline \multicolumn{5}{|l|}{ COPD and smoking status } \\
\hline Never smokers without COPD & 1670929 & 783 & 0.5 & Reference \\
\hline Never smokers with COPD & 41266 & 122 & 3.0 & 2.67 (2.09 to 3.40$)$ \\
\hline Ever smokers without COPD & 625104 & 761 & 1.2 & 1.97 (1.75 to 2.21$)$ \\
\hline Ever smokers with COPD & 17705 & 168 & 9.5 & 6.19 (5.04 to 7.61$)$ \\
\hline
\end{tabular}

*Subhazard ratios for incident lung cancer were modelled with mortality as a competing risk and adjusted for sex, body mass index (continuous) and Charlson comorbidity index (age as time scale).

COPD, chronic obstructive pulmonary disease. 


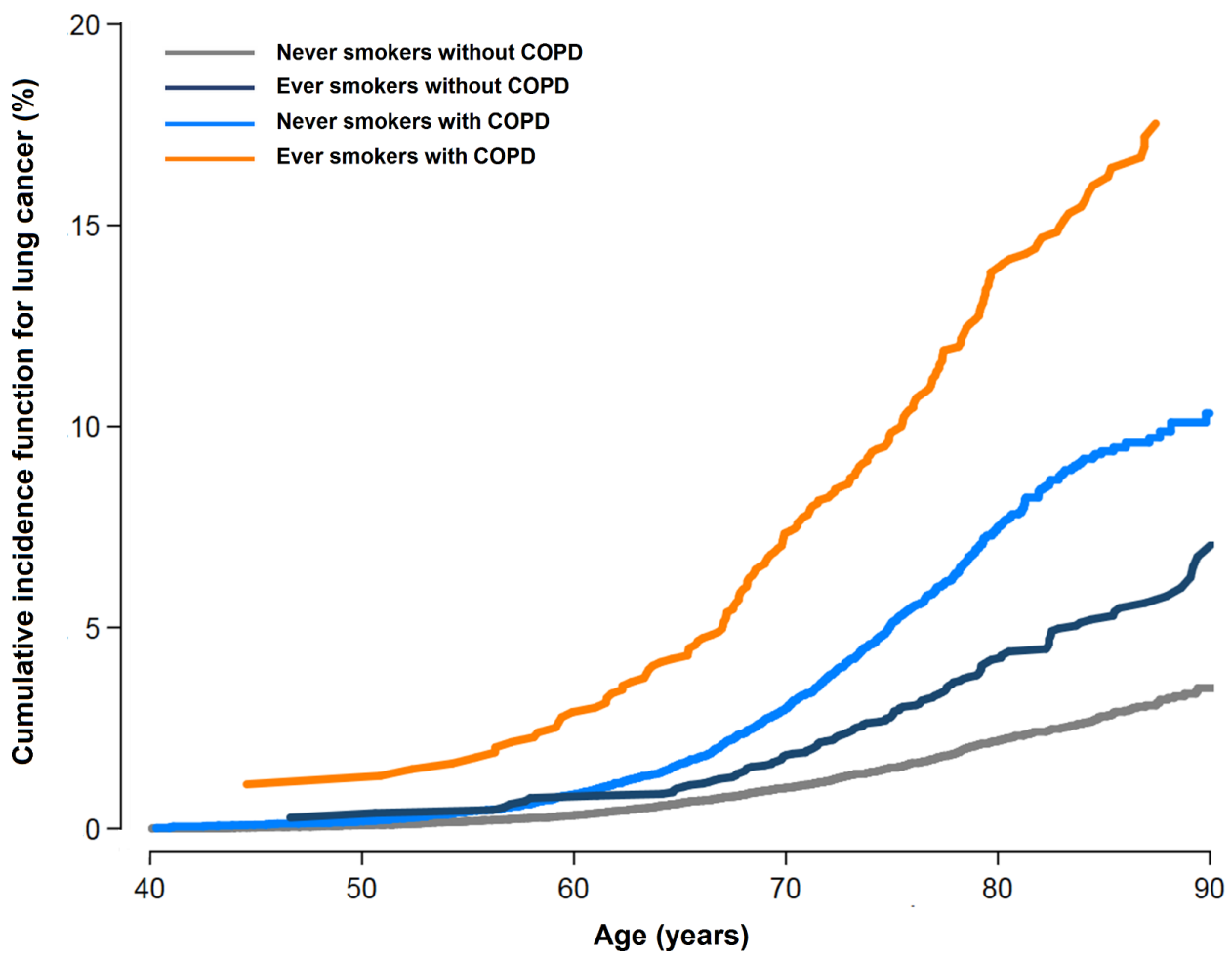

Figure 1 Cumulative incidence function for lung cancer by chronic obstructive pulmonary disease (COPD) and smoking status. COPD was considered as a time-varying exposure. Unexposed person-time was contributed by participants who did not develop COPD and by participants who developed lung cancer before COPD development. Cumulative incidence functions take into account competing risks from all-cause mortality.

with never smokers without COPD, the fully-adjusted subHR $(95 \% \mathrm{CI})$ for lung cancer in never smokers with COPD, ever smokers without COPD, and ever smokers with COPD were 2.67 (2.09 to 3.40$), 1.97$ (1.75 to 2.21 ), and 6.19 (5.04 to 7.61 ), respectively (table 2 ). When we conducted sensitivity analysis in propensity-score matched groups, the results were similar. Among study participants, $70.1 \%$ had at least one additional screening during follow-up. Among study participants who were never smokers at baseline, only $2.0 \%$ changed to smokers. When we conducted additional analysis using smoking status as the time varying variable, the results were similar (not shown).

\section{DISCUSSION}

In this large national cohort study, never smokers with COPD had over 2.6 times the incidence of lung cancer compared with never smokers without COPD. Furthermore, the risk of lung cancer in never smokers with COPD was similar compared with ever smokers without COPD.

Previous studies of COPD and lung cancer incidence were limited by a small number of never smokers with COPD that was insufficient to reliably estimate the association between COPD and lung cancer development in this group. ${ }^{45}$ In another large cohort study, lung cancer mortality was associated with both chronic bronchitis and emphysema, but not with chronic bronchitis alone, in never smokers. ${ }^{10}$ In this study, the presence of chronic bronchitis and emphysema was established by questionnaire. In our study, based on inpatient, outpatient, procedures, and medication claims, never smokers with COPD had over 2.6 times the incidence of lung cancer compared with never smokers without COPD. Interestingly, the risk of lung cancer development in never smokers with COPD was similar to the risk observed in ever smokers without COPD. Given that poor lung function in COPD is often a barrier to optimal lung cancer treatment due to increased risk of treatment-related morbidities, our study suggests that early detection of lung cancer in COPD patients may reduce the risk of treatment complications.

This study has several limitations. First, COPD severity based on spirometry was not available, thus we could not evaluate the impact of COPD severity on lung cancer incidence. Second, we did not have information on environmental/occupational exposures ${ }^{11}$ or severity of emphysema, ${ }^{12}$ which could be potential confounders for increased lung cancer risk in COPD. Finally, data on clinical outcomes were based on claims data and there might be misclassification of COPD or lung cancer. However, the NHIS routinely audits the claims ${ }^{6}$ and the data for cancer outcomes are considered highly reliable and have been used in numerous peer-reviewed publications. ${ }^{89}$

In conclusion, COPD was a strong independent risk factor for lung cancer incidence in never smokers. Furthermore, never smokers with COPD had a similar risk of lung cancer compared with ever smokers without COPD. Patients with COPD are at a high risk of lung cancer and future studies should evaluate whether COPD patients are candidates for lung cancer screening, irrespective of smoking status.

\section{Author affiliations}

'Division of Pulmonary and Critical Care Medicine, Department of Medicine, Samsung Medical Center, Sungkyunkwan University School of Medicine, Seoul, South Korea

${ }^{2}$ Center for Clinical Epidemiology, Samsung Medical Center, Seoul, South Korea ${ }^{3}$ Department of Clinical Research and Evaluation, SAIHST, Sungkyunkwan University, Seoul, South Korea

${ }^{4}$ Department of Internal Medicine, Konkuk University School of Medicine, Seoul, South Korea

${ }^{5}$ Division of Pulmonary, Allergy and Critical Care Medicine, Department of Internal Medicine, Seoul St Mary's Hospital, College of Medicine, The Catholic University of Korea, Seoul, South Korea

${ }^{6}$ Department of Thoracic and Cardiovascular Surgery, Samsung Medical Center, Sungkyunkwan University School of Medicine, Seoul, South Korea 
${ }^{7}$ Departments of Epidemiology and Medicine and Welch Center for Prevention, Epidemiology and Clinical Research, Johns Hopkins Medical Institutions, Baltimore, Maryland, USA

Contributors Author contributions: Conception and design: HYP, DK, EG, JC, OJK. Data analysis: DK, EG, JC. Data interpretation and manuscript writing: HYP, DK, SHS, $\mathrm{K}-\mathrm{HY}, \mathrm{CKR}, \mathrm{GYS}, \mathrm{HK}, \mathrm{YMS}, \mathrm{EG}, \mathrm{JC}$, OJK. Revision of the manuscript and contribution to intellectual content: HYP, DK, SHS, KHY, CKR, GYS, HK, YMS, EG, JC, OJK.

Funding This work was supported by the National Research Foundation of Korea (NRF) grant funded by the Korea government (MSIP) (no. 2017R1A2B2006435).

Competing interests None declared.

Patient consent for publication Not required.

Provenance and peer review Not commissioned; externally peer reviewed.

Open access This is an open access article distributed in accordance with the Creative Commons Attribution Non Commercial (CC BY-NC 4.0) license, which permits others to distribute, remix, adapt, build upon this work non-commercially, and license their derivative works on different terms, provided the original work is properly cited, appropriate credit is given, any changes made indicated, and the use is non-commercial. See: http://creativecommons.org/licenses/by-nc/4.0/.

\section{REFERENCES}

1 Young RP, Hopkins RJ, Christmas T, et al. COPD prevalence is increased in lung cancer, independent of age, sex and smoking history. Eur Respir J 2009;34:380-6.
2 Zhou Y, Wang C, Yao W, et al. COPD in Chinese nonsmokers. Eur Respir J 2009;33:509-18.

3 Skillrud DM, Offord KP, Miller RD. Higher risk of lung cancer in chronic obstructive pulmonary disease. A prospective, matched, controlled study. Ann Intern Med 1986;105:503-7.

4 Purdue MP, Gold L, Jarvholm B, et al. Impaired lung function and lung cancer incidence in a cohort of Swedish construction workers. Thorax 2007;62:51-6.

5 Mannino DM, Aguayo SM, Petty TL, et al. Low lung function and incident lung cancer in the United States: data from the first National Health and Nutrition Examination Survey follow-up. Arch Intern Med 2003;163:1475-80.

6 Lee J, Lee JS, Park S-H, et al. Cohort profile: the National Health Insurance ServiceNational Sample Cohort (NHIS-NSC), South Korea. Int J Epidemiol 2017:46:e15.

7 Chang Bae C, Soon Yang K, Jun Young L, et al. Republic of Korea. Health system review. Health Systems in Transition 2009;11.

8 Hwangbo Y, Kang D, Kang M, et al. Incidence of diabetes after cancer development: a Korean national cohort study. JAMA Oncol 2018;4:1099-105.

9 Park HY, Kang D, Lee $\mathrm{H}$, et al. Impact of chronic obstructive pulmonary disease on mortality: a large national cohort study. Respirology 2019;46.

10 Turner MC, Chen Y, Krewski D, et al. Chronic obstructive pulmonary disease is associated with lung cancer mortality in a prospective study of never smokers. Am J Respir Crit Care Med 2007;176:285-90.

11 Kc R, Shukla SD, Gautam SS, et al. The role of environmental exposure to noncigarette smoke in lung disease. Clin Trans/ Med 2018;7:39.

12 de Torres JP, Bastarrika G, Wisnivesky JP, et al. Assessing the relationship between lung cancer risk and emphysema detected on low-dose CT of the chest. Chest 2007:132:1932-8 